\title{
Afinidade Eletiva: Antoine-Laurent e Mme Lavoisier*
}

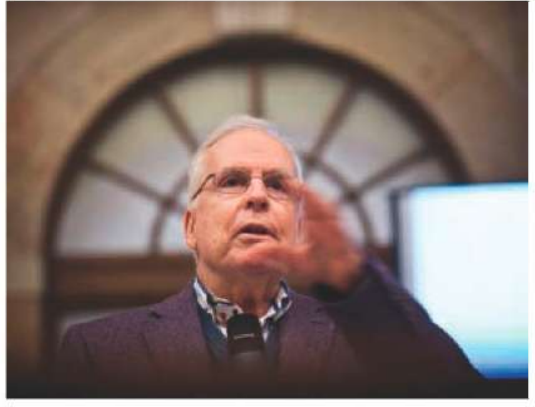

AfINIDADE

A química é uma história de afinidades: saber o que reage com quê. Em ciência, perceber é qualificar e quantificar. Os dois aspetos são igualmente importantes. Toda a gente sabe medir a temperatura; pouca gente sabe o que é a temperatura... Também se pode dizer que quase toda a gente sabe o que significa afinidade. Poucos (mesmo entre as químicas e os químicos) sabem que a afinidade química se mede pelo simétrico da energia de Gibbs da reação - uma quantidade que não pode ser medida diretamente, mas que pode ser calculada. Ao contrário dos eduqueses, os cientistas gostam de se apropriar de palavras comuns para batizar novos conceitos - os seis sabores (up, down e strange; charm, bottom e top) dos quarks, por exemplo. É o que acontece com a palavra afinidade: começou a ser usada no século XVI (1533) com o significado de relação, parentesco, semelhança, etc. Tal como as espécies, o significado das palavras evolui. No século XVII (1611), afinidade passou a significar, também, atração, inclinação, companheirismo (por exemplo, quando se fazia uma saúde,

\footnotetext{
* Conferência proferida no Amphiteatro de Chimica da Escola Polytechnica (Museu de Ciência, R. da Escola Politécnica, Lisboa) a 9 de fevereiro de 2012 por ocasiäo do encerramento das comemoraçöes do Ano Internacional da Quimica 2011 e inicio das celebrações do Centenário da Sociedade Portuguesa de Quimica

** Presidente da Comissão Nacional para o Ano Internacional da Quimica/Centenário da SPQ E-mail: jorge.calado@ist.utl.pt
}

bebia-se às respetivas inclinações) Finalmente, no século XVIII (1753), falava-se de afinidade como metáfora de atração química. (As datas referem-se ao primeiro uso registado na língua inglesa). Por exemplo, quando se percebeu que os hidrocarbonetos saturados (alcanos) eram pouco reativos, deu-se-lhes o nome de parafinas (que significa terem pouca afinidade para as outras substâncias).

\section{A contribuição de Goethe}

Foi um grande escritor alemão, Johann Wolfgang von Goethe (17491832), quem fez a ligação entre o significado literário (humano e emocional) e o significado químico de afinidade (Figura 1). Quem me conhece, sabe da minha adoração por Shakespeare. Pois bem, coloco em segundo lugar Goethe (com uma pitada de Schiller).

Goethe era tudo: poeta, romancista, dramaturgo, ensaísta, filósofo, pintor, biólogo, geólogo (colecionou perto de 18000 exemplares de rochas e minerais), físico (autor duma muito influente, mas errada, teoria das cores, "Zur Farben/ehre", 1810), etc. Um dos seus protegidos e grande amigo foi

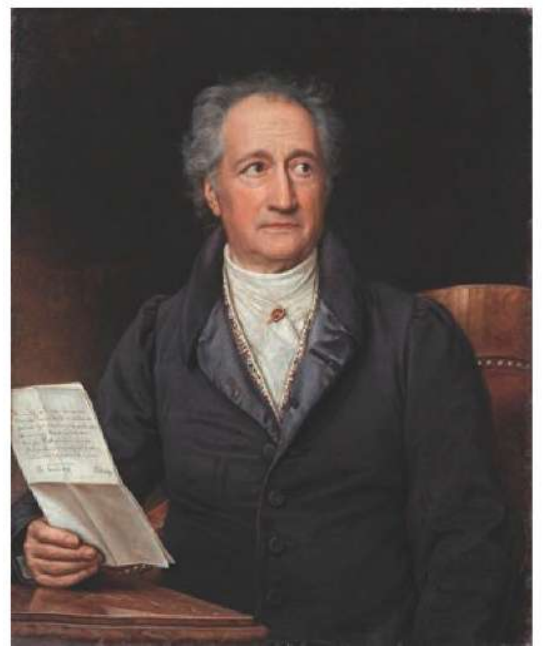

Figura 1 - JOSEF STIELER, Johann Wolfgang von Goethe, 1828
Johann Wolfgang Döbereiner (17801849), professor de química na Universidade de Jena (a cerca de $20 \mathrm{~km}$ de Weimar), a partir de 1810 (Figura 2). (Reparem nos nomes dos dois amigos: ambos Johann Wolfgang, isto é um caso de afinidades homónimas).

Entre as investigações de Döbereiner estão as propriedades catalisadoras do negro de platina (1821), nomeadamente na oxidação do etanol a ácido acético (vinagre), e a descoberta das famosas tríadas de elementos (1829), que anteciparam a tabela periódica de Mendeleev: a massa atómica do sódio é aproximadamente a média aritmética das do lítio e do potássio, e o mesmo acontece com o estrôncio (em relação ao cálcio e ao bário) e com o bromo (em relação ao cloro e ao iodo). Embora mais de 30 anos mais velho, Goethe frequentava semanalmente as aulas de Döbereiner e discutia com ele o conceito de afinidade química: porque é que certas substâncias mostram uma afinidade particular para outras?

No seu romance "Die Wahlverwandtschaften" (As Afinidades Eletivas), publicado em 1809, Goethe trata as relações pessoais e emocionais dos personagens como reações quími-

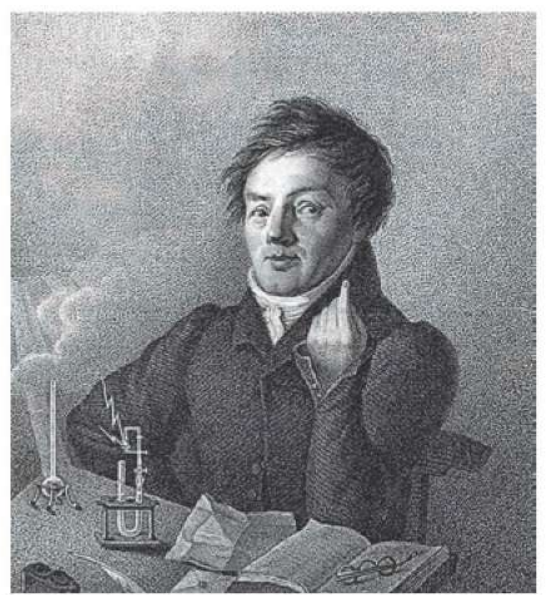

Figura 2 - Johann Wolfgang Döbereiner (1780-1849) 
cas (Figura 3). Tinha de ser um escritor alemão, dextro na morfologia e gramática alemãs, a trazer a química para a literatura. Reparem como a palavra do título - WAHLVERWANDTSCHAFTEN - pode ser lida como uma fórmula molecular ou reação química entre os seus três componentes, $\mathrm{A}+\mathrm{B}+\mathrm{C}$ : WAHL (eletivo); VERWANDT (relativo, parecido); SCHAFT (pau, traço-de-união). A formação de palavras novas à custa das afinidades entre palavras já existentes.

Nas palavras de A. Mega Ferreira, o romance de Goethe é "um lugar literário onde se debatem as questões da formação e da diluição dos laços interpessoais num grupo restrito de seres humanos, relacionando-os com o conceito científico de afinidade".

Tudo gira à volta de um casal adulto, inteligente e experiente: o Barão (Eduard Otto) e Charlotte, casados um com outro (ambos em segundas núpcias), e a viver numa abastada mansão senhorial, rodeados de belezas naturais que estão em vias de transformar (são ambos praticantes da arquitetura paisagista). Brincando com o fogo alquímico das relações humanas, os dois acham que há lugar para uma terceira e até uma quarta pessoa na sua intimidade doméstica. "Não há nada mais importante em qualquer circunstância do que a intervenção duma $3^{a}$ pessoa. Tenho visto amigos, irmãos e irmãs, amantes, casais cujas relações foram absolutamente alteradas e as suas posições completamente invertidas pelo advento aleatório ou intencional de outra pessoa", admite Charlotte.

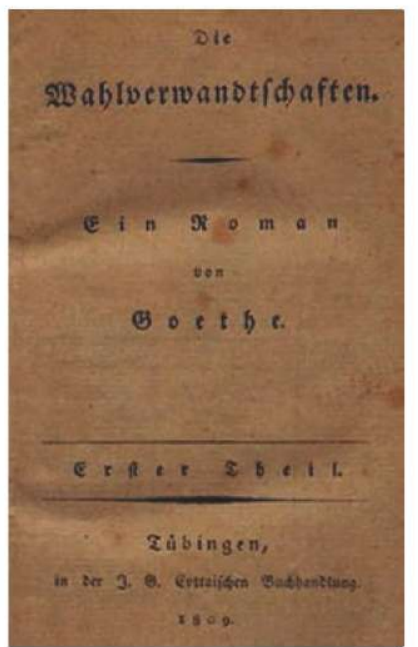

Figura 3-Die Wahlverwandtschaften, 1809
No célebre capítulo 4, Goethe avança uma discussão erudita sobre as reações químicas e as afinidades eletivas. As pessoas podem não ser números, mas são letras ou símbolos químicos, A, B, C, D. A está combinado (casado) com $B$, aparece $C$ e combina-se com este, $A C$, e liberta $B$. Se $B$ for um gás, terá mais dificuldade em encontrar parceiro. As cobaias vão ser o Capitão, o melhor amigo do Barão (também chamado Otto), e a jovem sobrinha de Charlotte, Ottilie. Inevitavelmente, Eduard e Ottilie apaixonam-se e o mesmo acontece com Charlotte e o Barão. Há ainda vários catalisadores, como o Conde e a Baronesa, e alguns atractores como o Arquiteto. O papel de terceiros é fundamental. Eduard sabe que o azeite e o óleo se podem combinar através de um sal alcalino (saponificação) e usa esta metáfora. Não vou contar o enredo. Apenas digo que há celebrações, renúncias, mortes e nascimentos (presume-se que ilegítimos), e que "As Afinidades Eletivas" são uma versão mais analítica e cerebral dos romances de Jane Austen (1775$-1817)$.

Mas o que me impressiona sobremaneira é o facto de a história se desenrolar num ambiente de arquitetura paisagista. Eduard e Charlotte iniciam um processo de grandes alterações da paisagem acidentada dos seus domínios, que pode ser vista como um campo de energia potencial onde se desenrola a reação emocional entre os personagens. Há montes e vales, bosques e lagos e caminhos tortuosos. Os personagens passeiam-se, combinam encontros fortuitos. É difícil não ver nestas maquinações uma metáfora dos mecanismo reacionais, os cumes e profundezas duma superfície de energia potencial, os píncaros do complexo ativado. Recomendo a leitura a quem tiver de ensinar os mistérios da cinética química.

\section{Antoine e Mme Lavoisier}

Como às vezes acontece - depois da teoria vêm as aplicações. Quando Goethe publicou "As Afinidades Eletivas" (1809), Mme Lavoisier tinha cinquenta anos e viveria por muitos e bons anos. Uma sobrevivente às maiores convulsões políticas do seu tempo, às vicissitudes da vida e aos desgostos e dramas pessoais, morreria em 1836, aos 78 anos. Como uma das missões do Ano Internacional da Química 2011 era celebrar as contribuições das mulheres para a ciência, Mme Lavoisier será a protagonista desta comunicação. Aproveita-se, também, para fazer justiça ao papel que teve na publicação do "Tratado Elementar de Química" (1789) do marido, finalmente traduzido em português!

Todos os presentes sabem que se deve a Antoine-Laurent Lavoisier (1743-1794) a grande revolução (francesa) química. Como em todas as revoluções, pelo caminho atropelou muitos. O que foi esquecido é que ele cresceu cientificamente como um diligente praticante dos quatro elementos: começou pela Terra, com a sua colaboração durante os anos 1760-70 no atlas geológico e mineralógico da França, empreendido por Jean-Etienne Guettard (1715-1786), continuou com a Água, estudando a potabilidade das águas dos poços e respetiva composição, para chegar à água pura (que tomaria para padrão), e iniciou-se na química pneumática dos Ares, às ordens do seu patrono, J. C. P. Trudaine de Montigny (1733-1777). Quanto ao Fogo, sabe-se que foi Lavoisier quem entendeu o fenómeno da combustão (combinação com o oxigénio), que está na base da referida revolução.

O ano crucial é 1768 , quando, aos 25 anos, Lavoisier foi eleito para a Academia das Ciências e resolveu investir a sua enorme fortuna pessoal - miIhões de euros, em moeda atual - na Ferme générale, um consórcio privado que cobrava, em nome do Governo, vários impostos indiretos (tabaco, álcool, sal), bem como os direitos aduaneiros de bens e produtos que entravam em Paris. O casamento não estava nos seus planos; mas estava nos de outro fermier général (arrendatário do Estado), Jacques-Alexis Paulze de Chasteignolles (1719-1794), diretor da Comissão do tabaco (onde trabalhava Lavoisier). Viúvo, tinha uma filha - uma menina prendada, de cabelo castanho e olhos azuis, educada num convento (a mãe morrera quando tinha três anos), que tocava cravo e 
harpa e aprenderia desenho e inglês (Figura 4). Marie-Anne Pierrette Paulze (1758-1836) - de seu nome - era requerida em casamento pelo influente Conde d'Amerval, um velho feio, de 50 anos, arruinado e sem ocupação. Pai e filha detestavam-no, e foi assim que Marie-Anne foi impingida ao assexuado Antoine-Laurent, em 1771. Lavoisier tinha 28 anos e a noiva 13. Sabe-se que o copo d'água incluiu duas sopas e nove pratos (peça de vitela e empada de borracho, frango de fricassé, picado de perdiz, perdiz com molho, torta assada, peru grelhado, galinha gorda com trufas e galinha desmembrada), mais quatro pratos de aves assadas (capão, galinhola, cerceta e pato), além de legumes, saladas, rissóis e frituras. Um bolo monumental coroado por duas figuras de açúcar representando os noivos, vinhos e o melhor café Moka.

O casamento foi consumado, Marie-Anne engravidou aos 15 anos, mas perdeu o bebé (1774) e nunca mais teve filhos. 1774 foi também o ano em que os Lavoisiers receberam a visita de Joseph Priestley (1733-1804), e em que o jovem (20 anos) e inexperiente Louis XVI subiu ao trono. No mesmo ano, Pierre-Samuel Dupont (1739-1817), um protegido do fisiocrata François Quesnay (1694-1774), emergiu como um poderoso economista e político na nova administração, e travou relações com os Lavoisiers, de quem se tornará o maior amigo e colaborador (Figura 5). Quatro anos mais velho que Antoine (e quase 20 em relação a Marie-Anne), ela tratá-lo-á familiarmente por "mon père".

Em 1776, Lavoisier foi nomeado para a Administração das Pólvoras e Salitres e o casal instalou-se no Pequeno Arsenal, depósito de pólvora da Bastilha. Foi aqui que Lavoisier criou um dos mais bem equipados laboratórios de investigação da Europa. Levantava-se às 5 horas da manhã, trabalhava no laboratório das 6 às 9 ; das 9 às 17 era funcionário do Estado (passava a manhã na Ferme générale e a tarde na Régie des Poudres ou na Academia Real das Ciências); depois da ceia, voltava ao laboratório, das 19 às $22 \mathrm{~h}$. Marie-Anne tornou-se na colaboradora indispensável do marido: musa, secretária e assistente, tradutora (inglês) e ilustradora. Não há dúvida de que a relação entre os dois foi cimentada pelo interesse comum pela ciência e, mais tarde, pela indústria, economia e finanças (do Estado): um caso de afinidade científica (química, em particular) que nunca foi afetado pelos múltiplos affaires amorosos de Marie-Anne. Lavoisier estava demasiado ocupado para se preocupar com isso.

Entretanto Lavoisier resolveu dedicar-se também à agricultura científica, e para isso comprou (1778), por 1,2 miIhões de euros, uma propriedade perto de Freschines, que foi ampliando até ter mais de mil hectares. Foi nesta altura, possivelmente aproveitando as ausências do marido em Freschines, que Marie-Anne iniciou uma relação com Dupont, um homem casado e pai de filhos. O ano é 1781, e a relação durará dez anos (até 1791), embora Dupont continue apaixonado por Marie-Anne até à morte (1817). Quanto a Lavoisier, deve ter sabido da relação, mas não se importou. Os dois cavalheiros permaneceram amigos e continuaram a colaborar em assuntos do Estado.

Ao contrário do marido, Madame apreciava a vida mundana, frequentava a ópera e não perdia uma exposição; nas horas vagas, desenhava e pintava. Tinha também uma conversa viva e inteligente, defendia ideias liberais, nomeadamente a criação duma monarquia constitucional. À 2. ${ }^{a}$ feira, os Lavoisiers abriam o seu Salon e recebiam os VIPes da época, sendo os cientistas particularmente bem vindos (entre eles, muitos britânicos). O francófilo Charles Blagden (17481820), assistente de Henry Cavendish (o descobridor do hidrogénio, em 1766), James Watt (1736-1819) e o já referido Priestley foram visitas assinaláveis; Joseph Black (1728-1799) não foi, mas mandou discípulos. Benjamin Franklin (1706-1790), que viveu em Paris entre 1776-1785, era um frequentador regular (Figura 6). (Refira-se, de passagem, que um dos interesses de Franklin era a aquisição de pólvora para a Revolução Americana). Marie-Anne pintou-lhe o retrato (1783) e está ainda por esclarecer se foi - ou não - sua amante (apesar de uma diferença de idades de mais de 50 anos).

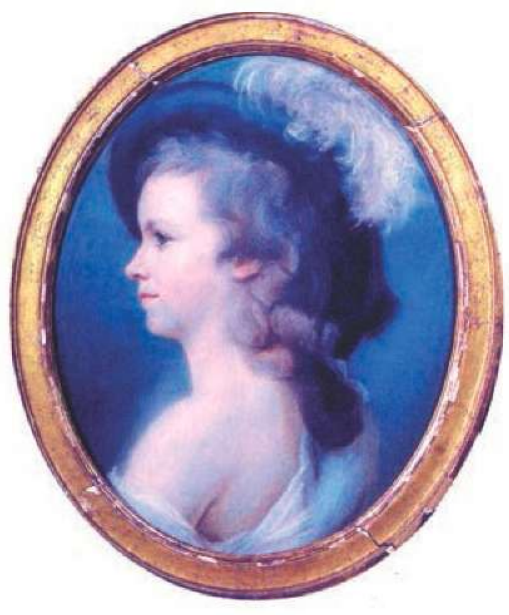

Figura 4 - Marie-Anne de Lavoisier, adolescente

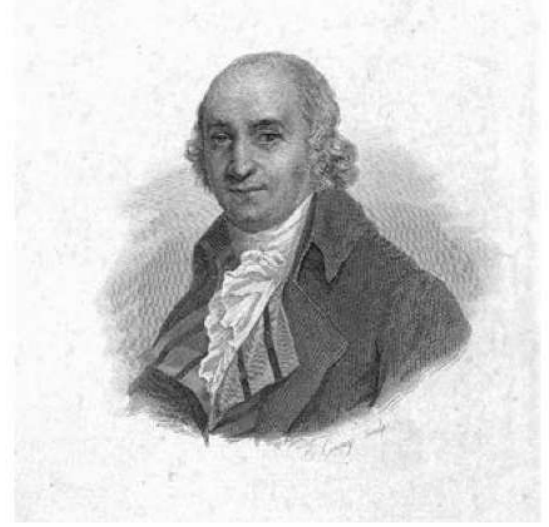

Figura 5 - Pierre-Samuel Dupont (1739-1817)

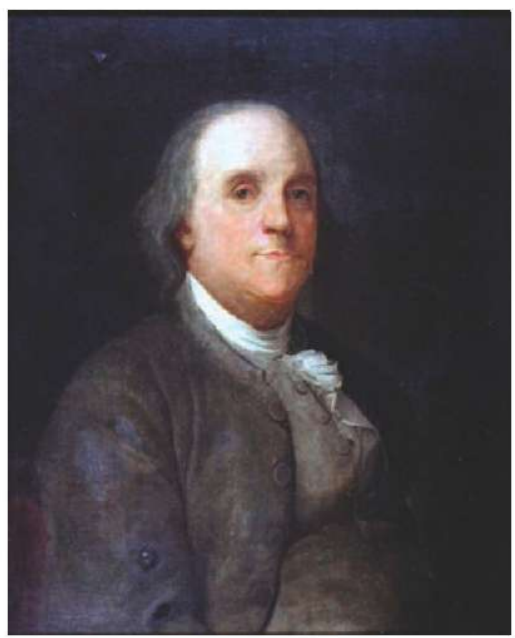

Figura 6 - MARIE-ANNE LAVOISIER, Benjamin Franklin (1706-1790), 1783-86

O que se sabe é que, em 1786 (aos 28 anos), Madame resolveu aperfeiçoar a sua queda para a pintura, tomando lições com Jacques-Louis David (1748-1825). Dois anos depois (1788) encomendava ao mestre o retrato do casal, pelo qual pagou o equivalente a 20000 euros (Figura 7). 


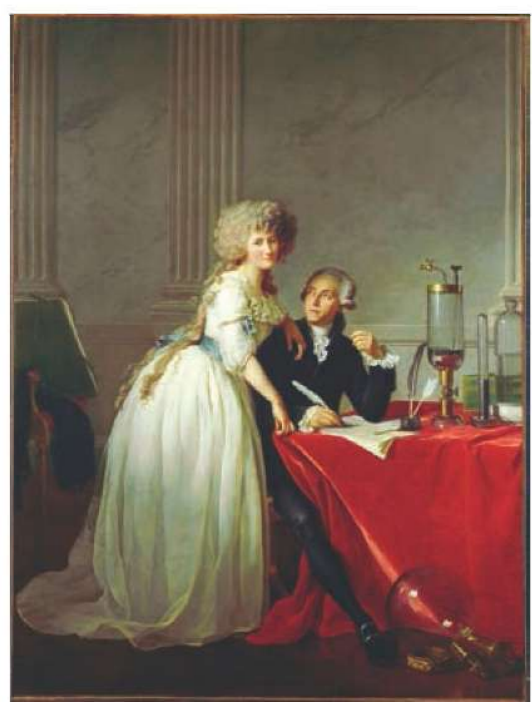

Figura 7 - JACQUES-LOUIS DAVID, AntoineLaurent Lavoisier e Sua Mulher, 1788

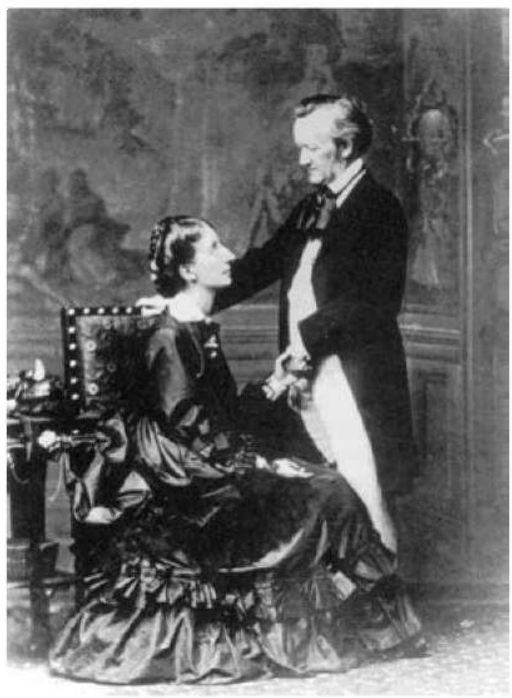

Figura 8 - Richard e Cosima Wagner, 1872 (Viena)

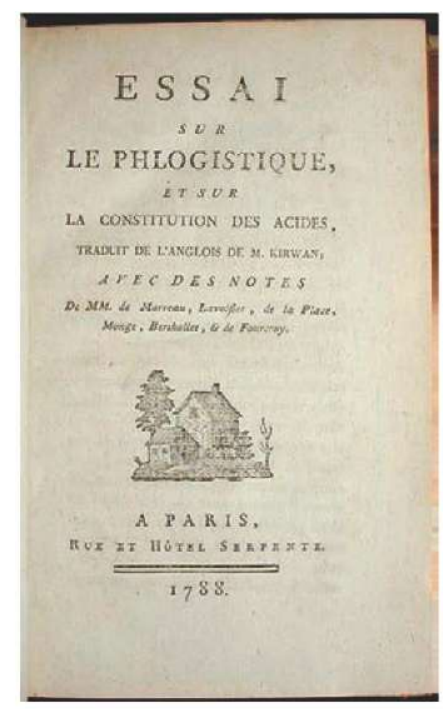

Figura 9 - Essai sur le phlogistique, 1788
Mais do que um retrato duplo, o quadro de David representa a apoteose duma colaboração indispensável, de igual para igual. Aliás, é ela quem domina a pintura, grande e frontal, com o marido a desempenhar o papel de galante admirador embevecido. O contraste com outro retrato duplo (desta vez, fotográfico) dum casal famoso Richard (1812-1883) e Cosima Wagner (1837-1930) - quase um século mais tarde, não podia ser maior. É Cosima quem está sentada (porque era mais alta do que Richard), e é ela quem contempla o marido em transe de adoração (Figura 8).

Marie-Anne não só assistia e participava nas experiências químicas, como tomava notas, desenhava os aparelhos e encarregava-se da correspondência com os químicos estrangeiros (Lavoisier não sabia inglês). Como rezava um poema do poeta e dramaturgo Jean-François Ducis (1733-1816), popular na altura:

Épouse et cousine à la fois, Sûre d'aimer et de plaire,

Pour Lavoisier, soumis à vos lois,

Vou remplissez les deux emplois,

Et de muse et de secrétaire.

As suas contribuições não se limitaram à química. 0 marido estava cada vez mais envolvido nas questões financeiras do Estado (em 1788, emprestou o equivalente a cerca de 270 milhões de euros à Caixa de Descontos, um banco privado, emissor de moeda), e não chegava para as encomendas. A dedicação exclusiva era uma figura então desconhecida. Reinava a curiosidade e $o$ apetite pelas funções mais diversas. Dupont (ou Du Pont, como passou a escrever o nome depois de enobrecido pelo Rei, em 1783) também não tinha mãos a medir; por volta de 1790 trabalhava em doze comissões! Era natural que os dois the pedissem ajuda. Assim, em 1787, Marie-Anne foi encarregada de reportar sobre a indústria têxtil (fiação, etc.) em Orléans - visitou fábricas, estudou a maquinaria e sua origem (inglesa) e escreveu um detalhado relatório, "Viagem a Orléans durante a Assembleia provincial de 17 Novembro de 1787 até 22 de Dezembro do mesmo ano".
UMA MULHER NA QUIIMICA

Estamos no século XVIII, um século de mulheres cultas, com predisposição para as ciências (filosofia natural). Outro caso notável foi o de Claudine, Mme Picardet (1735-1820), que viria a casar, em segundas núpcias, com Louis-Bernard Guyton de Morveau (1737-1816), autor do "Dicionário Químico" (1766), padrinho do calórico e um dos colaboradores de Lavoisier. Claudine era fluente em quatro línguas estrangeiras e traduziu numerosos textos químicos para francês, nomeadamente do sueco Carl Scheele (1742-1786), o primeiro descobridor do oxigénio; colaborou também com Lavoisier com muitas observações meteorológicas. Diga-se, de passagem, que Guyton de Morveau foi um dos químicos que pouco ou nada fez para salvar Lavoisier da guilhotina; Marie-Anne nunca Ihe perdoou.

Em 1788, Mme Lavoisier publicou a sua tradução anotada do "Ensaio do Flogisto", do químico irlandês Richard Kirwan (1733-1812), um livro de 180 páginas que tinha começado a ser traduzido também por Mme Picardet. Trata-se de um trabalho que Ihe exigiu uma preparação minuciosa. Discutiu questões químicas não só com o marido, mas também com Guyton de Morveau, Pierre-Simon Laplace (1749-1827), Gaspard Monge (17461818), Claude Berthollet (1748-1822) e Antoine Fourcroy (1755-1809), e escreveu um longo prefácio (revisto estilisticamente por Pierre Du Pont, que tinha a fama de escrever muito bem). Nas três Notas do tradutor, Marie-Anne criticou e corrigiu afirmações de Kirwan. Fala de 'atracões eletivas' e de 'afinidades', e sabe, por exemplo, que $\mathrm{o}$ ar saturado de humidade é mais leve (menos denso) do que o ar seco (basta comparar as massas moleculares do oxigénio e do nitrogénio com a massa molecular da água). Típico para a época, o nome da tradutora não consta da folha de rosto (Figura 9)!

As preocupações de Marie-Anne estendiam-se ainda ao grafismo das publicações. Para o frontispício do "Ensaio do flogisto" queria uma ilustração simbólica e elegante, e para isso aconselhou-se com Jean-Henri Hassenfratz (1755-1827), engenheiro 
de minas, físico e químico, assistente do marido e amigo íntimo do casal (Figura 10). Uma das sugestões visava uma alegoria à vitória do Espírito da química moderna sobre a Hipótese flogística. Pela mesma altura, os Lavoisiers tinham organizado, no Arsenal, uma mascarada com o auto-da-fé do flogisto (aproveitada por Carl Djerassi e Roald Hoffmann na sua peça, "Oxigénio", de 2001: A Vitória do $\mathrm{Ar}$ Vital sobre O Flogisto, com música de Lully, Rameau e Mozart). Nenhuma pegou, e o livro veio a lume em edição modestamente ilustrada. Marie-Anne e Jean-Henri andavam ambos na casa dos trinta anos, e hoje sabe-se que se desenvolveu entre eles aquilo a que os franceses chamam 'uma amizade particular'.

No ano seguinte - 1789 , o ano do início da Revolução Francesa - foi publicado o "Tratado elementar de química" de Lavoisier, profusamente ilustrado com pranchas da mão de Marie-Anne. Na fabulosa Coleção Lavoisier da Universidade de Cornell, fui encontrar as provas corrigidas, pela mão de Madame, de algumas dessas pranchas; a da Prancha IV continha até um post-it anexado pela ilustradora! Marie-Anne desenhou também as experiências sobre a respiração conduzidas por Lavoisier e pelo seu assistente, o químico e fisiologista Armand Seguin (1767-1835), entre 1789-1794, em que se autorretratou (à direita, sentada a uma secretária, a tirar notas, Figura 11).

Entretanto a situação política complicava-se. A grande fortuna pessoal de Lavoisier e o seu envolvimento (bem

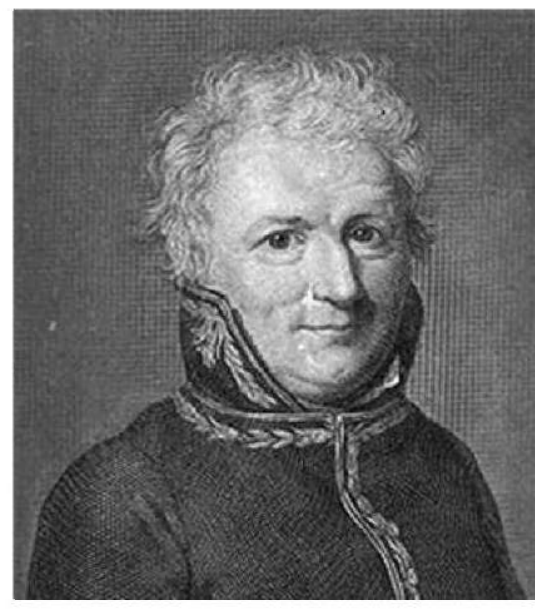

Figura 10 - Jean-Henri Hassenfratz (1755-1827) como o do seu sogro e cunhados) na Ferme générale, tornavam-no suspeito. Arranjara grandes inimigos entre os poderosos, nomeadamente Jean-Paul Marat (1743-1793), que tinha pretensões a químico. Como tantos outros, Lavoisier pensou em fugir para a Grã-Bretanha ou para a América, e nesse sentido escreveu a Joseph Black e a Benjamin Franklin. Mas, como quem não deve, não teme, o casal Lavoisier deixou-se ficar em Paris. Em 1793, foi obrigado a largar o Arsenal, e instalou-se numa mansão no boulevard de la Madeleine. Lavoisier foi, finalmente, preso a 28 de novembro de 1793. Marie-Anne tentou desesperadamente salvá-lo, mas, em tempos turbulentos, poucos amigos estavam dispostos a interceder em seu favor. A última esperança residia em Antoine Dupin (1758-1829), deputado-relator do julgamento. Marie-Anne descobriu que Jean-Baptiste Pluvinet (17541814), um dos boticários que fornecia reagentes a Lavoisier, era primo da cunhada de Dupin. Este fez saber que Madame Lavoisier nada lhe pedira, mas que estava disposto a recebê-la. No entanto, Marie-Anne deitou tudo a perder quando, em vez de defender o marido, atacou ferozmente a revolução e os seus sequazes. Sem apelo nem agravo, a 8 de maio de 1794 , Lavoisier foi guilhotinado, juntamente com 37 arrendatários do Estado. Dupont passou à clandestinidade, e era o filho, Eleuthère Irénée (1771-1834), quem the dava notícias da cidadã Lavo (como Mme passou a ser conhe- cida entre os íntimos). Presa a 14 de junho, Marie-Anne passou 65 dias na prisão. Dupont foi igualmente preso. Finalmente, a 27 de julho Robespierre foi guilhotinado e acabou o Terror.

\section{As PaIXões de MME LAVOISIER}

Os primeiros anos após a libertação foram difíceis. Magra, quase esquelética, Marie-Anne viveu da caridade de um velho criado. Dupont propôs-se casar com ela - ela tinha, então, 36 anos, ele, 55 - mas Madame fez-se esquiva, como era seu hábito. Seria por causa do dinheiro? O certo é que Dupont devia aos Lavoisiers o equivalente a 300000 euros - um empréstimo antigo para montar uma imprensa - que não tinha condições para o pagar. Desiludido, Dupont acabou por casar (1795) com a viúva de Pierre Poivre (1719-1786), um antigo administrador nas ilhas Maurícias. Em 1797 foi novamente preso, mas conseguiu safar-se passando por octogenário (tinha 58 anos)! Emigrou para a América em 1799, com os fiIhos, noras, netos e enteada, tendo-se instalado em New Jersey, perto de Nova lorque. Entretanto, Marie-Anne iniciara a luta para recuperar os seus bens, incluindo os 5000 volumes da biblioteca do pai e o duplo retrato por David. Aos poucos, conseguiu. Com a emergência de Napoléon Bonaparte como 1. ${ }^{\circ}$ Cônsul (1799), Marie-Anne retomou o seu lugar na sociedade. $\mathrm{Na}$ América, Dupont continuava apaixonado por ela (apesar de novamente casado); Marie-Anne, por seu turno,

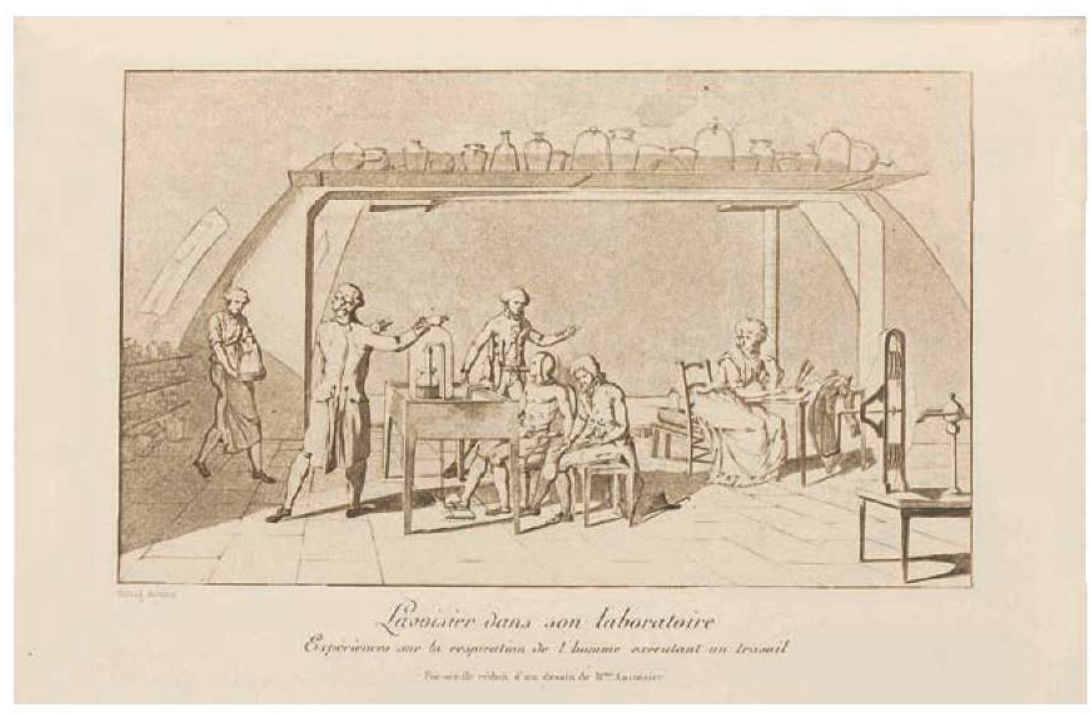

Figura 11 - Lavoisier e Seguin realizando experiências sobre a respiração (desenho de Marie-Anne Paulze) 
implorava o seu regresso a França (possivelmente para que ele the pagasse a dívida).

Outros homens entravam na vida de Marie-Anne. Por exemplo, Benjamin Thompson (1753-1814), Conde de Rumford, acabado de chegar a Paris em outubro de 1801, depois de fundar a Royal Institution em Londres: "um grande e belo homem de 1,83 m, feições regulares, com brilhantes olhos azuis e cabelos castanhos escuros", cinco anos mais velho que Marie-Anne (Figura 12). Houve atracão mútua, à primeira vista. Rumford frequentava - Salão Lavoisier praticamente todos os dias, e tomou o pequeno-almoço com Marie-Anne no dia em que regressou a Inglaterra. Esta sentia-se entusiasmada com a companhia do cientista, queria ser a sua secretária, revivendo, talvez, a sua colaboração com Antoine Lavoisier. Mas, pelo sim pelo não, continuava a escrever afetuosamente a Dupont..., agora em vias de regressar a França, a pedido de Napoléon, para negociar a venda da Louisiana (francesa) à América. De volta em 1802, Dupont procurou logo Marie-Anne, mas esta recusou-se a recebê-lo durante vários dias. Tinha topete! No ano seguinte selava-se o acordo de venda da Louisiana (por 240 milhões de euros) que duplicava a área da jovem nação americana, pois englobava também aquilo que viria a ser Arkansas, Dakota, lowa, Kansas, Missouri, Montana, Nebraska e Oklahoma!

Em 1802, um novo personagem, Marc Auguste Pictet (1752-1825), um físico

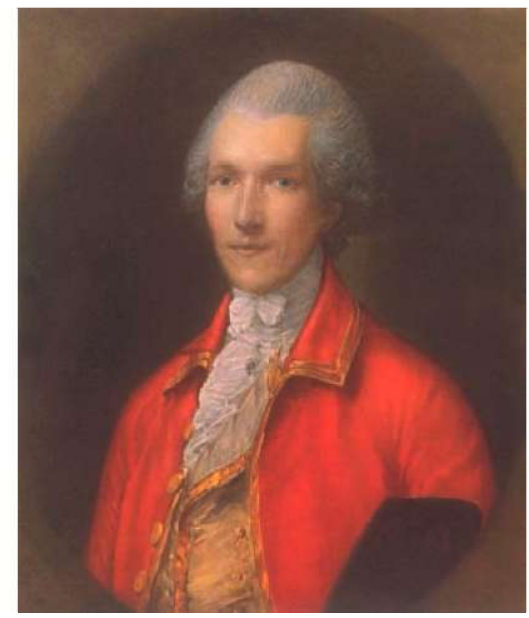

Figura 12 - Benjamin Thompson, Conde de Rumford (1753-1814) e astrónomo suíço, chegava a França, a pedido de Bonaparte (Figura 13). Depressa se tornou a coqueluche dos Salões, disputado por todas as anfitriãs, mas Marie-Anne não teve dificuldade em o conquistar. Levou-o à Ópera para ver "As Bodas de Fígaro", de Mozart, e tornou-se sua amante.

O já referido Charles Blagden foi outro personagem assíduo (Figura 14). Conheciam-se desde 1783, quando Blagden jantou com os Lavoisiers, em Paris. A história é curiosa: o solteirão Blagden quisera desposar Sarah, a fiIha de Rumford, mas este opôs-se e aconselhou-o a ligar-se a Mme Lavoisier. Entretanto, Rumford começara a apreciar os dotes de Marie-Anne e a dizer-Ihe coisas como: "Não concebo nada mais doce do que viver com vós, trabalhar todo o dia e, de seguida, dormir nos vossos braços". Blagden acabou expulso de França pela polícia de Napoléon, e regressou a Munique na companhia de Rumford. (Mais tarde, diria que tinham sido tudo intrigas de Rumford para afastar um rival à mão de Marie-Anne...).

O certo é que, pouco tempo depois, Mme Lavoisier aceitou um convite de Pictet para o visitar na Suiça e irem admirar o Mer de Glace (glaciar). Combinou a viagem com Rumford e ficaram os dois instalados em casa de Pictet. Em carta a Sarah (1774-1852), a sua filha americana, Rumford escrevia: "Conheci, em Paris, esta muIher muito amável que, creio, não porá nenhumas objeções a tomar-me por esposo, e que será, de todos os pontos de vista, um excelente partido

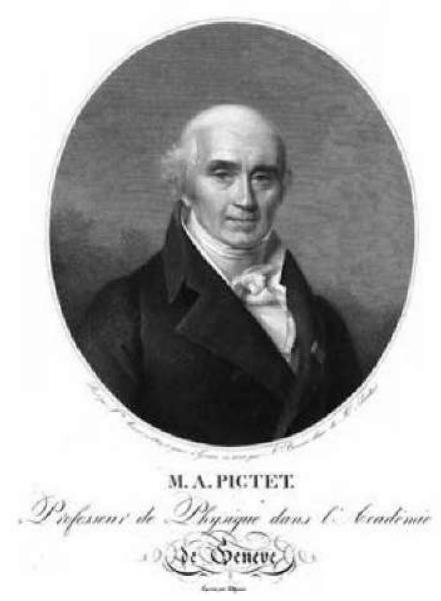

Figura 13 - Marc Auguste Pictet (1752-1825) para mim. É viúva, sem filhos, nunca os teve; tem mais ou menos a minha idade, goza de boa saúde e mostra-se muito agradável ao mundo. Possui uma boa fortuna pessoal; a sua reputação é excelente; tem uma casa bem posta, recebe os grandes filósofos, os sábios e os escritores mais eminentes do nosso tempo, ou mais exatamente, de Paris; acima de tudo, é a bondade em pessoa. [...] É espirituosa (no sentido inglês do termo); [...]. Foi muito bela no seu tempo, e ainda hoje, aos 46 ou 48 anos, está bem parecida; de altura média, mais roliça do que magra. Tem muita vivacidade e escreve admiravelmente bem".

Coitado, enganava-se redondamente. Uma coisa é o convívio social; outra, a vida em comum, no dia-a-dia. Pela primeira vez, Marie-Anne defrontava uma personalidade mais forte do que a sua. Casaram em outubro de 1805 , mas poucos meses depois, já Marie-Anne se queixava amargamente a Dupont. Rumford queria uma vida pacata, dedicada ao estudo; ela preferia o bulício e a vaidade dos Salões. Ele fechava-a à chave; ela regava as preciosas roseiras do marido com água a ferver. Nas palavras do Abbé André Morellet (1727-1819): "São dois machos que não conseguem acasalar!" Marie-Anne ainda tentou fazer expulsar Rumford de França, como cidadão britânico, mas sem êxito. Separaram-se finalmente em junho de 1809 , quando ele foi viver para Auteil.

Quem é a verdadeira Mme Lavoisier? No seu melhor, uma mulher inteligente e culta, com forte personalidade e notáveis contribuições para o avan- 
ço da química (em colaboração com o primeiro marido). O seu Salão foi considerado "a primeira sociedade de Paris, a mais elegante, a mais maravilhosa". Aí dava bailes e concertos, e fez ouvir Maria Malibran (1808-1836), a mais célebre cantora do seu tempo. Mas Mme Lavoisier era também pedante, snobe e avarenta, sendo o testemunho dos seus contemporâneos. Os últimos anos foram de nítida decadência física e mental. Embora baixa de estatura $(1,55 \mathrm{~m})$, deixou-se engordar, transformou-se numa "espécie de velho turco". A elegância deu em deboche: usava calão nas conversas, levantava as saias para aquecer o rabo. Prosper Mérimée (1803-1870), o autor da novela "Carmen", descreveu-a como "150 quilos de carne limpa". Marie-Anne Pierrette Paulze Lavoisier, Condessa de Rumford, morreu em 1836, aos 78 anos. Só falta escrever e compor a ópera sobre esta mulher célebre, com muitas e variadas afinidades.

\section{CODA}

Avanço uma vintena de anos. No Inverno de 1859/60, Michael Faraday (1791-1867) dedicou as suas habituais Lições de Natal, destinadas a um público juvenil, às várias forças da natureza e às relações de umas com as outras. Faraday tinha então 68 anos, estava adoentado com uma constipação e declarou-se na $2 .^{a}$ meninice, um jovem a comunicar com outros jovens. Faraday escolheu a gravitação, a eletricidade, a coesão e a afinidade química. Quatro forças, o que não é despiciendo! Sim, afinidade química! Faraday distinguiu a coesão (que se refere a forças entre partículas duma mesma espécie, por exemplo, numa barra de ferro, que a mantêm rígida) da afinidade química (que se refere a forças entre partículas de espécies diferentes, por exemplo entre o oxigénio e o hidrogénio para formar água).

As lições foram publicadas postumamente em 1873 (Faraday morreu em 1867), editadas e com prefácio assinado por William Crookes (18321919), descobridor do tálio, identificador do plasma como o $4 .^{\circ}$ estado da matéria, etc.

Crookes viu o livro como uma resposta à pergunta: $O$ que é que apareceu primeiro, a Matéria ou a Força? Nas suas palavras: "Somos incapazes de conceber a matéria sem a força ou a força sem a matéria".

Trata-se duma reformulação da velha questão da galinha e do ovo, ou da pescada (que antes de o ser já o era). Mal comparado, é como o começo do Evangelho Segundo S. João: "No princípio havia o Verbo; e o Verbo estava em Deus; e o Verbo era Deus". É este o mistério da criação.

\section{Agradecimento}

Ao Professor Mário N. Berberan-Santos pela cuidadosa leitura do texto e pertinentes sugestões.

\section{Atualidade Científica}

\section{EXPERIÊNCIAS NO CERN POSSIBILITAM A OBSERVAÇÃO DE UMA PARTÍCULA CONSISTENTE COM O BOSÃO DE HIGGS}

Num seminário ocorrido no CERN, que funcionou como uma antecipação da maior conferência de Física de Partículas deste ano, - ICHEP2012, que teve lugar em Melbourne, as equipas das experiências ATLAS e CMS apresentaram os seus últimos resultados preliminares na procura da partícula de Higgs. Ambas as experiências possibilitaram a observação de uma nova partícula numa região de massa na gama de $125-126 \mathrm{GeV}$.

A porta-voz da experiência ATLAS, Fabiola Gianotti, afirmou que "os nossos dados indicaram sinais claros de uma nova partícula, num nível de 5 sigma, na região de massa de aproximadamente $126 \mathrm{GeV}$; no entanto, é necessário ainda algum tempo para preparar estes resultados para publicação".

Por outro lado, o porta-voz da experiência CMS, Joe Incandela, comunicou resultados preliminares que indicam a presença de um sinal 5 sigma a aproximadamente $125 \mathrm{GeV}$, acrescentando que "esta é certamente uma nova partícula que nós sabemos ser um bosão, o bosão mais pesado encontrado até ao momento". Adicionalmente, Incandela reforçou o carácter extremamente significativo desta descoberta, que deverá ser cuidadosamente verificada e confirmada.

Os resultados preliminares apresentados baseiam-se em dados recolhidos em 2011 e 2012, sendo que os dados de 2012 ainda se encontram sob análise. Espera-se que uma melhor e mais completa interpretação destas observações emirja no final do ano à medida que o LHC (Large Hadron Collider) possibilite experiências mais pormenorizadas.

O passo seguinte será a determinação da natureza específica da partícula e do seu significado na nossa compreensão do universo. A questão será estabelecer se estas propriedades correspondem às previstas para o há muito procurado bosão de Higgs, o elemento final que deveria completar o Modelo Padrão da Física de Partículas, ou se será algo desconhecido e não previsto e, consequentemente, ainda mais exótico. O Modelo Padrão descreve as partículas fundamentais que constituem toda a matéria visível no universo e as forças que atuam entre estas partículas. No entanto, supõe-se que toda a matéria visível represente apenas $4 \%$ do total da matéria existente. Assim, uma versão mais exótica da partícula de Higgs poderia ser a ponte para a compreensão de $96 \%$ do universo que ainda permanece obscurecido.

A identificação positiva das características da nova partícula deverá demorar ainda um tempo considerável, implicando a recolha de muito mais dados. No entanto, quaisquer que sejam as propriedades da partícula de Higgs, a sua identificação representa um considerável passo em frente no nosso conhecimento da estrutura fundamental da matéria.

(adaptado do comunicado para a imprensa do CERN de 04/07/2012, http://press.web.cern.ch/press/PressReleases/ Releases2012/PR17.12E.html)

Paulo Brito (paulo@ipb.pt) Instituto Politécnico de Bragança 


\section{Antoine-Laurent LAVOISIER}

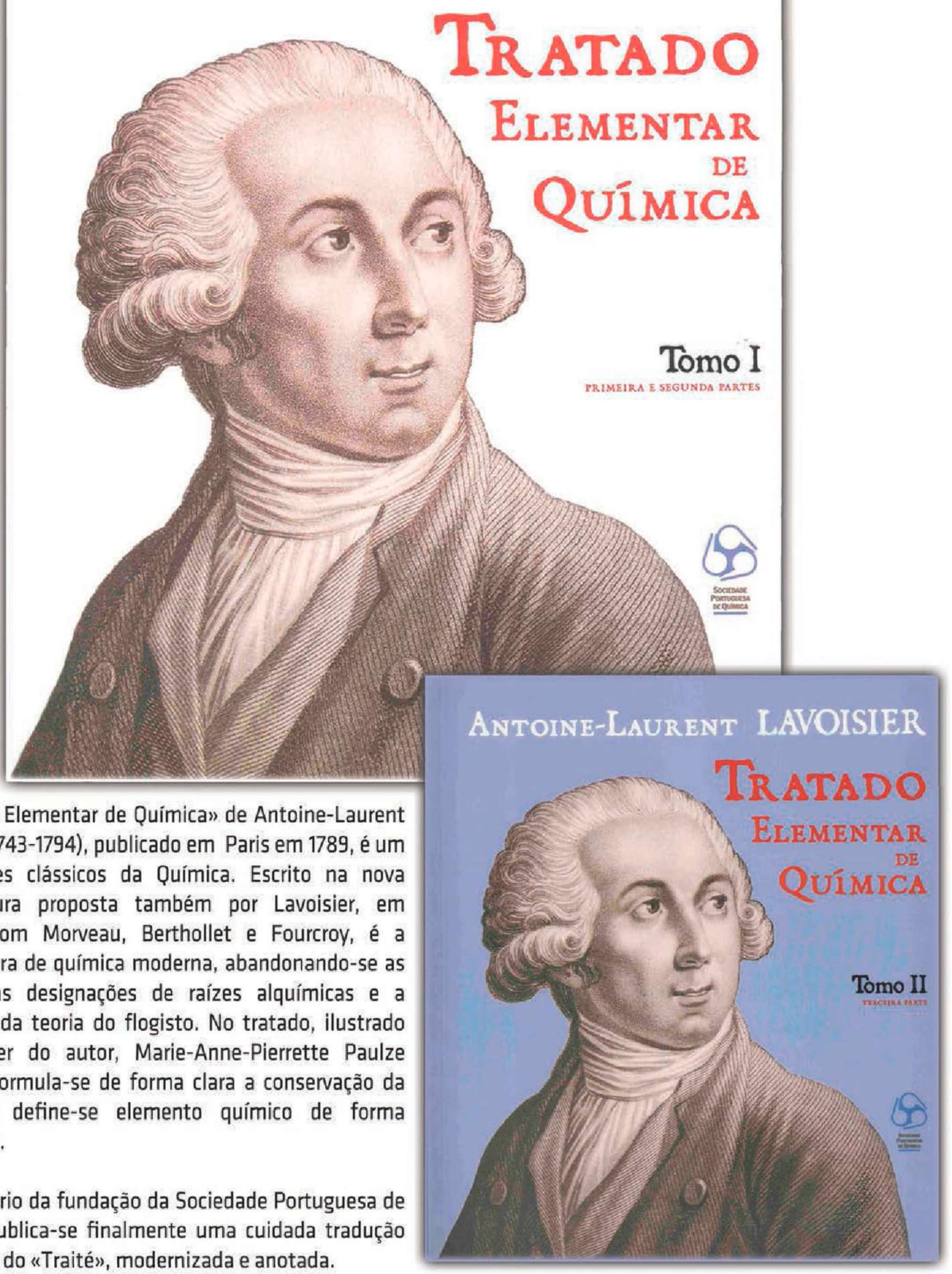

0 "Tratado Elementar de Química» de Antoine-Laurent Lavoisier (1743-1794), publicado em Paris em 1789, é um dos grandes clássicos da Química. Escrito na nova nomenclatura proposta também por Lavoisier, em conjunto com Morveau, Berthollet e Fourcroy, é a primeira obra de química moderna, abandonando-se as inadequadas designações de raízes alquímicas e a desacreditada teoria do flogisto. No tratado, ilustrado pela mulher do autor, Marie-Anne-Pierrette Paulze Lavoisier, formula-se de forma clara a conservação da matéria e define-se elemento químico de forma operacional.

No centenário da fundação da Sociedade Portuguesa de Química, publica-se finalmente uma cuidada tradução portuguesa do «Traité», modernizada e anotada. 